\title{
Conformational energy and structure in canonical and noncanonical forms of tRNA determined by temperature analysis of the rate of $s^{4} U 8-C 13$ photocrosslinking
}

\author{
WAYNE HUGGINS, TATJANA SHAPKINA, and PAUL WOLLENZIEN \\ Department of Molecular and Structural Biochemistry, North Carolina State University, Raleigh, North Carolina 27695, USA
}

\begin{abstract}
Bacterial tRNAs frequently have 4-thiouridine $\left(s^{4} U\right)$ modification at position 8 , which is adjacent to the $C_{13-G 22-m^{7} G 46}$ base $^{4}$ triple in the elbow region of the tRNA tertiary structure. Irradiation with light in the UVA range induces an efficient photocrosslink between $s^{4} \cup 8$ and $\mathrm{C} 13$. The temperature dependence of the rate constants for photocrosslinking between the $s^{4} U 8$ and $\mathrm{C} 13$ has been used to investigate the tRNA conformational energy and structure in Escherichia coli tRNA ${ }^{\mathrm{Val}}$, tRNA $^{\text {Phe }}$, and tRNA ${ }^{\text {fMet }}$ under different conditions. Corrections have been made in the measured rate constants to compensate for differences in the excited state lifetimes due to tRNA identity, buffer conditions, and temperature. The resulting rate constants are related to the rate at which the $s^{4} U 8$ and $\mathrm{C} 13$ come into the alignment needed for photoreaction; this depends on an activation energy, attributable to the conformational potential energy that occurs during the photoreaction, and on the extent of the structural change. Different photocrosslinking rate constants and temperature dependencies occur in the three tRNAs, and these differences are due both to modest differences in the activation energies and in the apparent $s^{4} U 8-C 13$ geometries. Analysis of tRNA $^{\mathrm{Val}}$ in buffers without $\mathrm{Mg}^{2+}$ indicate a smaller activation energy $\left(\sim 13 \mathrm{~kJ} \mathrm{~mol}^{-1}\right)$ and a larger apparent $\mathrm{s}^{4} \mathrm{U} 8-\mathrm{C13}$ distance $(\sim 12 \AA)$ compared to values for the same parameters in buffers with $\mathrm{Mg}^{2+}\left(\sim 26 \mathrm{~kJ} \mathrm{~mol}^{-1}\right.$ and $0.36 \AA$, respectively). These measurements are a quantitative indication of the strong constraint that $\mathbf{M g}^{2+}$ imposes on the tRNA flexibility and structure.
\end{abstract}

Keywords: RNA tertiary structure; photocrosslinking rates; activation energy; conformational energy; $\mathrm{T}_{1}$ excited state lifetimes

\section{INTRODUCTION}

The tRNA L-shaped tertiary structure is critical to many of its biological functions and there has been a continuing interest in the tRNA structure in translation (Yarus and Smith 1995; Yarus et al. 2003; Ogle and Ramakrishnan 2005). The connection between divalent ions and the stabilization of the tRNA tertiary structure has been addressed by several approaches. Binding analysis indicates that at least one $\mathrm{Mg}^{2+}$ in $\mathrm{tRNA}^{\mathrm{fMet}}$ (Cohn et al. 1969; Stein and Crothers 1976a,b) or two to three $\mathrm{Mg}^{2+}$ in tRNA ${ }^{\text {Phe }}$ (Lynch and Schimmel 1974; Römer and Hach 1975) are bound at high affinity sites and are associated with formation of the tertiary structure. The locations for the strong binding sites for $\mathrm{Mg}^{2+}$ are suggested by the crystal structure; two likely locations are at a site between the D loop (at nucleotides 19-20) and the T loop (at nucleotides

Reprint requests to: Paul Wollenzien, Department of Molecular and Structural Biochemistry, North Carolina State University, Raleigh, NC 27695, USA; e-mail: paul_wollenzien@ncsu.edu; fax: (919) 515-2047.

Article published online ahead of print. Article and publication date are at http://www.rnajournal.org/cgi/doi/10.1261/rna.656907.
59-60), and at a site in the sharp turn around nucleotides 8-12 between the $5^{\prime}$ strand of the acceptor stem and the $5^{\prime}$ strand of the D stem (Jack et al. 1977; Holbrook et al. 1977; Hingerty et al. 1978). Hydrodynamic experiments indicate an overall more extended shape in the tRNA at magnesium concentrations below $100 \mu \mathrm{M}$ (Eisinger et al. 1970; Danchin and Gueron 1970; Römer et al. 1970; Willick and Kay 1971; Robison and Zimmerman 1971). Quantitative measurements made by a hydrodynamic method (Friederich and Hagerman 1997; Hagerman 1997) and by gel mobility shift (Friederich et al. 1998) show that above $3 \mathrm{mM} \mathrm{Mg}^{2+}$ the interstem angle between the acceptor stem and anticodon stem is nearly the same as that observed in the crystal structure, but at micromolar $\mathrm{Mg}^{2+}$ concentrations the interstem angle is $\sim 150^{\circ}$.

Favre and coworkers (1975) used UVA irradiation $(\lambda>324 \mathrm{~nm})$ of various Escherichia coli tRNAs to activate the 4-thiouridine at position $8\left(\mathrm{~s}^{4} \mathrm{U} 8\right)$ and showed that it specifically crosslinks to nucleotide $\mathrm{C} 13$. The rate for the photocrosslinking reaction at $25^{\circ} \mathrm{C}$ is different for different tRNAs and depends on the buffer conditions (Favre et al. $1975,1979)$. It was also found that a mutation in the 
D stem of $\left(\right.$ sus $\left.^{+}\right)$tRNA $^{\text {Trp }}$ caused a decrease the rate of photocrosslinking compared to value seen in the (wildtype) tRNA ${ }^{\text {Trp }}$; this was taken as evidence for a conformational difference due to the alteration of the tRNA structure in the D stem (Favre et al. 1975; Favre and Thomas 1981). In addition, the photocrosslinking rate for tRNA ${ }^{\text {Phe }}$ was reduced by more than twofold when it was irradiated in a complex with tRNA synthetase (Favre et al. 1979). These studies indicate that the photocrosslinking reaction is very sensitive to conformational differences in the tRNA (Favre et al. 1975).

A quantitative model for the photocrosslinking process will help to connect differences in photocrosslinking rates to differences in the molecular properties. Information relevant to the mechanism came from our analysis of RNARNA photocrosslinks in ribosomal RNA induced by UV irradiation (Wilms et al. 1997; Shapkina et al. 2004) or by UVA irradiation of ribosomes containing ${ }^{4} \mathrm{U}$ (Nanda and Wollenzien 2004). These are both zero-length crosslinking reactions, like the $s^{4} \mathrm{U} 8-\mathrm{C} 13$ crosslink in tRNA, and, for both of these reactions, formation of the photocrosslinks depends on the direct contact and correct orientation of the two participating nucleobases. The availability of the atomic structure of the $30 \mathrm{~S}$ ribosomal subunit (Wimberly et al. 2000) allowed calculation of parameters that describe the internucleotide geometry at the sites where photocrosslinks had been observed. These measurements indicated a correlation between the reciprocal $\mathrm{Cl}^{\prime}-\mathrm{Cl}^{\prime}$ internucleotide distances and the photocrosslinking frequencies; the correlation coefficients have values between 0.39 to 0.7 using the Thermus thermophilus $30 \mathrm{~S}$ structure (Wimberly et al. 2000) or two E. coli 30 S structures (Schuwirth et al. 2005). These correlations and the comparison of the data for the UV- and UVA-s ${ }^{4} U$-induced crosslinks are consistent with reaction mechanisms that involve transient movements, which occur during the excited electronic state lifetime of the nucleobase, to bring the pairs of nucleobases from their equilibrium positions to the arrangement needed for photoreaction, rather than mechanisms in which there are stable alternate local conformations at the crosslinking sites (Huggins et al. 2005). An important feature of this mechanism is that the transition state for the photoreaction is reached without the system having to go through any higher potential energy. The tRNA tertiary structure at $s^{4} U 8-C 13$ suggests that a similar situation exists in the tRNA, and the same mechanism is assumed in generating an empirical equation to describe the rate of photocrosslinking.

The correlation coefficients between crosslinking frequencies and internucleotide distances are less than unity, so another factor must also affect the crosslinking frequencies. For the 16S rRNA it is likely that local flexibility, determined by hydrogen bonding and packing density, is responsible for inhibition at many potential sites and the modulation of the frequency at the sites where photo- crosslinks occur (Huggins et al. 2005; W. Huggins, K. Nanda, S.K. Ghosh, T. Shapkina, and P. Wollenzien, unpubl.). If this is the case, then the rate of photocrosslinking should increase as the temperature increases to reflect greater accessibility to the precise structures needed for photoreaction, which is determined by the conformational potential energy landscape. Such a response should allow the determination of the activation energy for the movement of the two nucleobases that participate in the photoreaction.

The temperature dependence of the rate of photocrosslinking for tRNA ${ }^{\mathrm{fMet}}$, $\mathrm{tRNA}^{\text {Phe }}$, and tRNA ${ }^{\mathrm{Val}}$ under different conditions has been investigated in this report. The data of Favre et al. (1975) that the photocrosslinking reaction follows first order kinetics are confirmed, and we further show that the rate constants increase with temperature and follow Arrhenius behavior, so that an activation energy can be determined. The apparent geometry at the photocrosslinking site also can be calculated for tRNA under different conditions. The measurements show that differences in geometry and flexibility can be separately determined by this approach. The data quantitatively confirm the stabilization of the canonical form of the tRNA by $\mathrm{Mg}^{2+}$.

\section{RESULTS}

\section{Determination of apparent photocrosslinking rate constants by gel electrophoresis analysis of irradiated tRNA}

UVA irradiation was done on $\left[{ }^{32} \mathrm{P}\right] 3^{\prime}$ end-labeled E. coli tRNA $^{\mathrm{fMet}}$ and tRNA ${ }^{\mathrm{Val}}$ for $1-20 \mathrm{~min}$ to induce the $\mathrm{s}^{4} \mathrm{U} 8$ C13 photocrosslink (Fig. 1) previously characterized by Favre et al. (1975) and Favre (1990). The separation of the tRNAs by electrophoresis on $8 \%$ polyacrylamide gels resulted in the appearance of a faster migrating band in
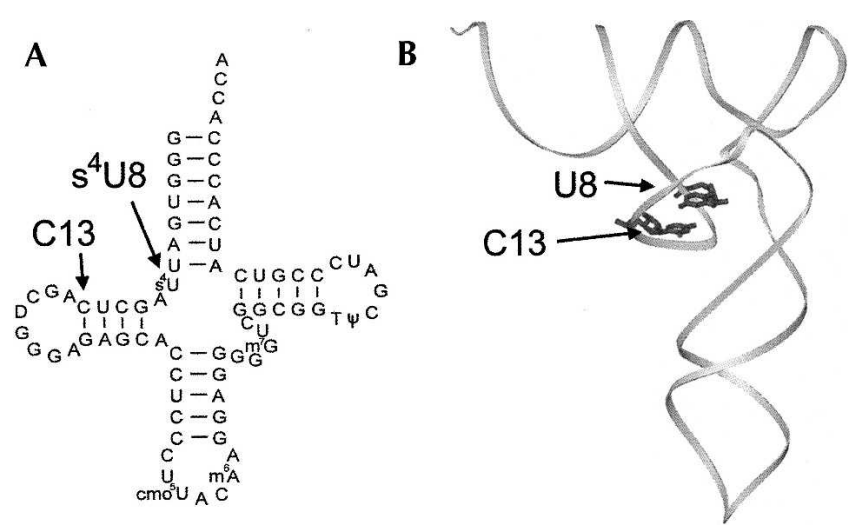

FIGURE 1. Location of the $s^{4} U 8-C 13$ photocrosslinking site in the tRNA secondary and tertiary structures. (A) Cloverleaf structure and sequence of $E$. coli tRNA ${ }^{\mathrm{Val}}$ with the $\mathrm{s}^{4} \mathrm{U} 8$ and $\mathrm{C} 13$ nucleotides indicated. (B) Location of U8 and C13 in the yeast tRNA ${ }^{\text {Phe }}$ tertiary structure. U8 is not thiolated in yeast tRNA ${ }^{\text {Phe }}$. 
the irradiated samples (Fig. 2A), rather than a slower mobility band, which would be expected for a molecule with a covalent loop (Lemaigre-Debreuil et al. 1991; Behlen et al. 1992; Wilms et al. 1997). To confirm that this faster band contained the $\mathrm{s}^{4} \mathrm{U} 8-\mathrm{C} 13$ photocrosslink, RNA from both bands was isolated and subjected to partial alkaline hydrolysis and RNA sequencing (Supplemental Material). In the RNA from the faster moving band, $\mathrm{C} 13$ was involved in intramolecular crosslink; its partner must be $s^{4} U 8$, since that is the only nucleotide that absorbs the wavelengths used. The sequencing experiments ruled out other crosslinks involving $s^{4} \mathrm{U} 8$ for the tRNA in solution. In addition, the gel electrophoresis analysis showed that there is some background radioactivity present at the position of the crosslinked tRNA even without irradiation and that not all of the original tRNA is photoreactive (Fig. 2A). The maximum amount of crosslinking in different samples is $70 \%-90 \%$ of the total. The background and maximum reaction need to be taken into account when determining the extent of reaction (see Materials and Methods).

The progress of the $s^{4} \mathrm{U} \times \mathrm{C} 13$ crosslink formation was followed by plotting the fraction of crosslinked tRNA ${ }^{\mathrm{fMet}}$ and $\mathrm{tRNA}^{\mathrm{Val}}$ at $0^{\circ} \mathrm{C}$ or $45^{\circ} \mathrm{C}$ versus time (Fig. 2B). The $\mathrm{s}^{4} \mathrm{U} \times \mathrm{C} 13$ crosslinking reaction is faster for $\mathrm{tRNA}^{\mathrm{fMet}}$, and the maximum amount is reached by $5 \mathrm{~min}$ of irradiation (Fig. 2B). In comparison, for the tRNA ${ }^{\mathrm{Val}}$ photoreaction the maximum amount of crosslink formation is reached after longer times and has a greater response to temperature than that seen for tRNA ${ }^{\mathrm{fMet}}$ (Fig. 2B). For both tRNAs, the reactions go to the same total extent at all temperatures studied. The fit of these curves with a single rate indicates that the entire photoreactive sample behaves with the same kinetics. The tRNAs need to be renatured for reproducible results, indicating that the rates are attributable to a property of the native structure.

Plots of natural logarithm of the fraction of unreacted tRNA versus time were done to determine if the reactions were first order and to determine the apparent rate constants (Fig. 2C). For both tRNAs, irradiations at both temperatures produced straight lines confirming a first order reaction. These data rule out temperature-dependent photoreactions other than crosslink formation that would prevent calculation of the photocrosslinking rate constant.
A

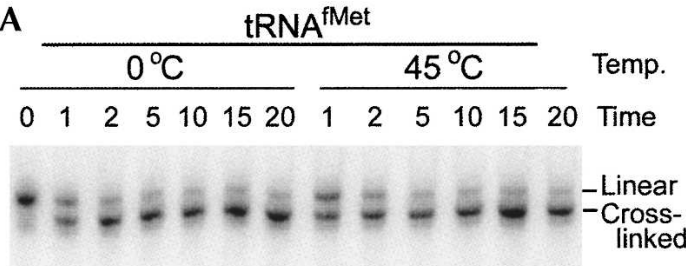

B

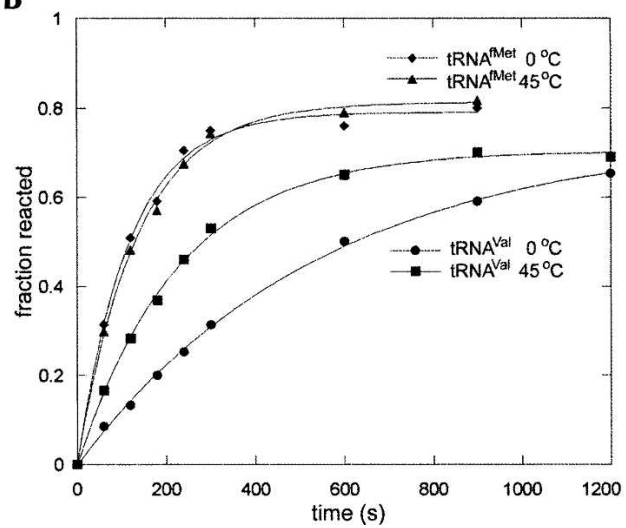

C

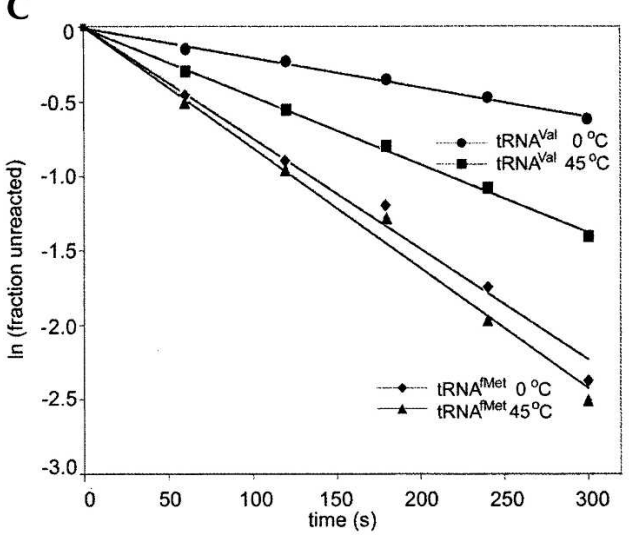

FIGURE 2. Analysis of kinetics of crosslink formation. (A) Gel electrophoresis separation of irradiated tRNA. tRNA ${ }^{\mathrm{fMet}}$ and tRNA ${ }^{\mathrm{Val}}$ were $3^{\prime}$ end exchange-labeled and irradiated in HiFi buffer with wavelengths $>320 \mathrm{~nm}$ for the indicated times at $0^{\circ} \mathrm{C}$ and $45^{\circ} \mathrm{C}$. Bands 1 and 2 separate after electrophoresis on $8 \%$ polyacrylamide urea gel and contain the uncrosslinked and crosslinked tRNA as confirmed by RNA sequencing (Supplemental Material). (B) Time course of photocrosslinking for tRNA ${ }^{\mathrm{fMet}}$ and tRNA ${ }^{\mathrm{Val}}$. Plot of fraction crosslinked versus irradiation time (in seconds) for tRNA ${ }^{\mathrm{fMet}}$ and tRNA ${ }^{\mathrm{Val}}$ at $0^{\circ} \mathrm{C}$ and $45^{\circ} \mathrm{C}$ as indicated in the figure. The irradiations were done in a buffer containing $20 \mathrm{mM}$ Tris ( $\mathrm{pH}$ 7.5), $100 \mathrm{mM} \mathrm{NH}_{4} \mathrm{Cl}$, and $20 \mathrm{mM} \mathrm{Mg}{ }^{2+}$. The curves were fitted using parameters for the first order rate constants and for the total amount reactive. The total extent of crosslinking for tRNA ${ }^{\mathrm{fMet}}$ and tRNA ${ }^{\mathrm{Val}}$ is $0.80 \pm 0.01$ and $0.72 \pm 0.02$, respectively. $(C)$ First order plot of rate of photocrosslinking. The logarithm of the fraction of tRNA unreacted for the $s^{4} \mathrm{U} 8 \times \mathrm{C} 13$ photocrosslink in tRNA ${ }^{\mathrm{fMet}}$ and tRNA ${ }^{\mathrm{Val}}$ is plotted versus time for the irradiations at $0^{\circ} \mathrm{C}$ and $45^{\circ} \mathrm{C}$. 


\section{Correction of measured photocrosslinking rate constants for differences in excited state $T_{1}$ lifetimes between tRNAs and at different temperatures}

Different tRNAs have different $s^{4} U$ excited state lifetimes (Favre 1990), and corrections have been made to the measured photocrosslinking rate constants to compensate for the longer or shorter times for reaction for the $s^{4} U$ in different tRNAs. The factors for these corrections are listed in the Supplemental Materials. In addition, for a particular tRNA, there may be differences in the excited state lifetimes due to other temperature-dependent or buffer effects. For $s^{4} U$, the photoreactive state is the $T_{1}$ state derived from the $S_{1}$ state by intersystem crossing. Intersystem crossing is complete for $\mathrm{s}^{4} \mathrm{U}$ (Favre 1990, Favre et al. 1998), and the formation of neither the $S_{1}$ nor $T_{1}$ states is expected to be temperature dependent. However, there are several possible fates for the $T_{1}$ state besides photochemistry, including nonradiative energy transfer, radiative deexcitation (phosphorescence), collisional quenching, and nonradiative deexcitation, which would alter the excited state lifetime. Measurements made in buffers containing chloride ion, which quenches the $T_{1}$ excited state (Favre 1990), or acetate ion indicate that collisional quenching does not occur as long as the tRNA is in the native conformation (data not shown). Of the remaining processes, nonradiative deexcitation must account for the majority of the deexcitation (Favre 1990) and this could be temperature dependent (Turro 1991). To determine if this were the case, the phosphorescence emission intensity, which reflects the excited state lifetime, was measured at different temperatures; it was seen that all of the tRNAs exhibit decreases in phosphorescence emission intensity as the temperature increases. Factors to correct the measured photocrosslinking rate constants were calculated from the emission intensities using emission at $25^{\circ} \mathrm{C}$ as the reference temperature. The correction factors for the temperature effect are listed in the Supplemental Material.

\section{Arrhenius plots to determine activation energies for photocrosslinking}

Rate constants for a photochemical reaction depend on the maximum rate of the photochemistry and, through the Boltzmann relationship, on an activation energy $\left(E_{\mathrm{a}}\right)$ associated with bringing the reactants into the transition state (Turro 1991). For the tRNA photocrosslinking reaction, the activation energy is attributable to the conformational potential energy change needed to move the photoreactive bonds of $s^{4} \mathrm{U} 8$ and $\mathrm{C} 13$ away from their relaxed equilibrium positions and into van der Waals contact and correct alignment for reaction. The rate constant could also depend on the entropy change associated with reaching the transition state, although for a unimolecular reaction this is usually negligible (Jencks
1969). This would be part of the preexponential term in the rate constant equation. In tRNA this could result from changes in the interaction with solvent or ions or changes in the conformational entropy. It will be seen that the preexponential term varies by $>20$-fold under different conditions, and it is very unlikely that this difference is due to differences in the entropy change (see Discussion). On the other hand, we had already observed that photocrosslinking frequencies tend to be larger for sites in the rRNA where the internucleotide distance is smaller (Huggins et al. 2005). Therefore the expression for the crosslinking rate constant should contain the inverse of the $s^{4} \mathrm{U} 8-\mathrm{C} 13$ internucleotide distance to incorporate this dependence. This gives the empirical equation

$$
k_{1, \mathrm{corr}}=A(1 / \Delta R B D) e^{(-E a / R T)},
$$

where $k_{1}$, corr is the measured first-order rate constant corrected for differences in the excited state lifetime values; $A$ is the factor that incorporates the rate of the photochemical reaction as well as instrumentation factors; $\triangle R B D$ is the distance between the centers of the C4-S4 bond of $s^{4} \mathrm{U} 8$ and the center of the C5-C6 bond of C13 minus the distance between the bonds at direct contact, $3.4 \AA$; $E_{\mathrm{a}}$ is the activation energy; and $R$ and $T$ are the gas constant and temperature.

The activation energy can be determined by the Arrhenius method by finding the slope of the dependence of $\ln$ $\left(k_{1, \text { corr }}\right)$ on $1 / T$ :

$$
\ln \left(k_{1, \text { corr }}\right)=\ln [A(1 / \Delta R B D)]-E_{a} / R T .
$$

Favre and coworkers (1975) previously characterized three different classes of $E$. coli tRNAs depending on whether their rates for photoreaction at $25^{\circ} \mathrm{C}$ were faster, slower, or equal to bulk unpurified E. coli tRNA. Three tRNAs were used to investigate the temperature dependence of the photocrosslinking rate: $\mathrm{tRNA}^{\mathrm{fMet}}$ (faster rate than bulk tRNA), tRNA ${ }^{\text {Phe }}$ (slower rate than bulk tRNA), and tRNA ${ }^{\text {Val }}$ (rate equal to that of bulk tRNA). Each tRNA was $\left[{ }^{32} \mathrm{P}\right]$ labeled and renatured in HiFi buffer $(50 \mathrm{mM}$ Tris at $\mathrm{pH} 7.5,30 \mathrm{mM} \mathrm{KCl}, 70 \mathrm{mM} \mathrm{NH}{ }_{4} \mathrm{Cl}, 3.5 \mathrm{mM} \mathrm{MgCl}_{2}, 8$ $\mathrm{mM}$ putrescine, $0.5 \mathrm{mM}$ spermidine) before irradiation as described in the Materials and Methods. Samples were irradiated for $1 \mathrm{~min}$ at temperatures from $0^{\circ} \mathrm{C}$ to $50^{\circ} \mathrm{C}$ to obtain apparent $k_{1}$ values. The $k_{1}$ values were corrected by multiplying by the factors to compensate for differences in the excited state lifetime intrinsic to each tRNA and due to temperature (Supplemental Material). Plots of corrected rate constants versus temperature for the three tRNAs are shown in Figure 3A.

The photocrosslinking rate constants increase with temperature for all three tRNAs. At $25^{\circ} \mathrm{C}$ the largest rate constant occurs in tRNA ${ }^{\mathrm{fMet}}, 0.022 \mathrm{sec}^{-1}$, which is nearly 
A

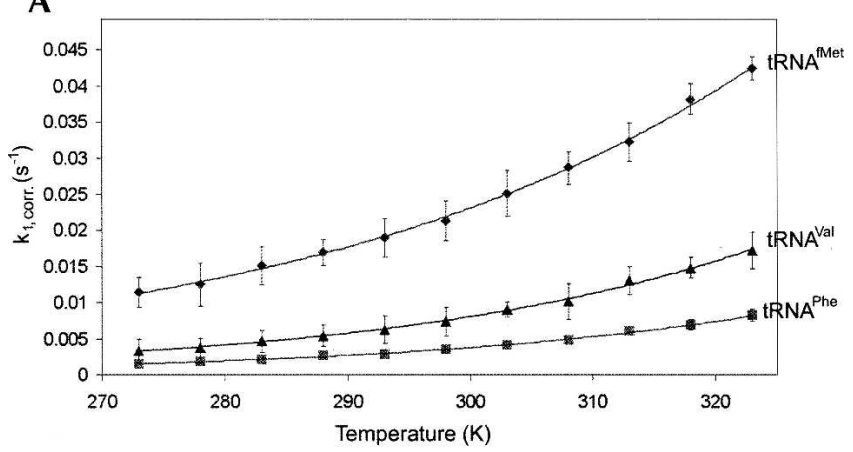

B

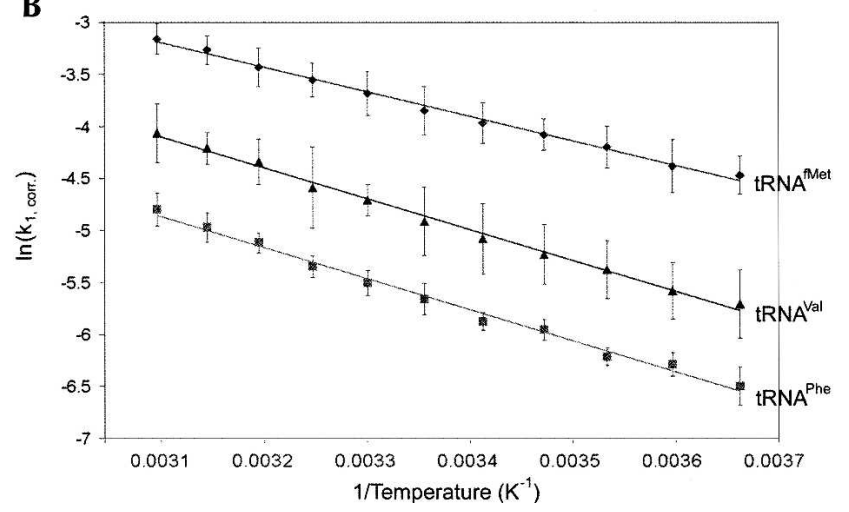

FIGURE 3. Temperature dependence of rate constants for formation of the $\mathrm{s}^{4} \mathrm{U} \times \mathrm{C} 13$ crosslink in $\mathrm{tRNA}^{\mathrm{fMet}}, \mathrm{tRNA}^{\mathrm{Val}}$, and tRNA ${ }^{\text {Phe }} .(A)$ First order rate constants calculated from 1-min irradiations at different temperatures and corrected for changes in excited state lifetimes. The fitted lines are exponential functions. Uncertainty bars are standard deviations of measurements at each temperature. (B) Arrhenius plots for the corrected first order rate constants. The fitted lines are linear regression lines.

three times the rate constant for tRNA $\mathrm{Val}, 0.0077 \mathrm{sec}^{-1}$, and six times the rate constant for tRNA ${ }^{\text {Phe }}, 0.0036 \mathrm{sec}^{-1}$ (Fig. 3A; Table 1). This trend is in good agreement with the results of Favre et al. (1975), although the absolute values between the tRNAs are different than in their report, but this can be attributed to differences in irradiation and buffer conditions and to the fact that the rate constants have been corrected for excited state lifetime differences.

Arrhenius plots were done with the data (Fig. 3B). The appearance of the plots for the three tRNAs are very similar, but there is a significantly smaller slope in the regression line for tRNA ${ }^{\mathrm{fMet}}$ compared to the two other tRNAs, which corresponds to an activation energy $\sim 5 \mathrm{~kJ}$ $\mathrm{mol}^{-1}$ less than for either tRNA ${ }^{\mathrm{Val}}$ or tRNA ${ }^{\text {Phe }}$.

\section{Calculation of internucleotide distances for $s^{4} U 8-C 13$ for the different tRNAs}

Rearrangement of Equation 1 allows calculation of the apparent extent of movement of the photoreactive bonds
(C4-S4 of $s^{4} \mathrm{U} 8$ and $\mathrm{C} 5-\mathrm{C} 6$ of $\left.\mathrm{C} 13\right)$ during the photocrosslinking reaction:

$$
\Delta R B D=A e^{(-E a / R T)} / k_{1, \text { corr }},
$$

where all terms are the same as in Equation 1 . Since $k_{1 \text {, corr }}$ and $E_{\mathrm{a}}$ are experimentally determined, this provides a method to determine the distance between the reactive bonds at $25^{\circ} \mathrm{C}$ under different conditions if the value of the preexponential factor $A$ is known. Since the reactive bonds have to be in van der Waals contact at the time of photoaddition, the calculation is an indication of what their distance separation must be in the equilibrium structure. $A$ was determined by postulating that there is a single value for it for all three tRNAs. High resolution structures for the E. coli tRNAs are not available, so the atomic structures of yeast tRNA $^{\text {fMet }}$ (Basavappa and Sigler 1991), tRNA ${ }^{\text {Phe }}$ (Shi and Moore 2000), and tRNA ${ }^{\text {Asp }}$ (Comarmond et al. 1986) were used to calculate values of $\triangle R B D$ for initiator tRNA and for elongator tRNA. With these values, $A$ was calculated from the experimentally determined $k_{1}$, corr and $E_{\mathrm{a}}$ values for each tRNA. These values were averaged and then used to recalculate $\triangle R B D$ for each tRNA.

The data and calculations of the distances between the reactive bonds at $25^{\circ} \mathrm{C}$ for the three tRNAs in $\mathrm{HiFi}$ are summarized in Table 1 . The rate constants are partly determined by the activation energy term of the rate equation. However the activation energies for tRNA ${ }^{\text {Phe }}$ and tRNA ${ }^{\mathrm{Val}}$ are nearly the same, but there is a twofold difference in the rate constant. The correction made for the difference in the excited state lifetimes contributes to the rate difference, but, even without that correction, a difference exists in the rate constants that can be attributed to a difference in the geometries of the molecules. For tRNA ${ }^{\mathrm{fMet}}$, the much higher rate constant is correlated to the lower activation energy; however, the rate constant would be even greater if tRNA ${ }^{\mathrm{fMet}}$ had an $\mathrm{s}^{4} \mathrm{U} 8-\mathrm{C} 13$ internucleotide distance similar to either of the other tRNAs. Therefore in this case the discrepancy between the rate constant and the activation energy again can be attributed in a reasonable way to a difference in the internucleotide distance.

\section{Calculation of force constant for the conformational flexibility in the tRNA}

The activation energy for the photocrosslinking reaction must originate in the tRNA tertiary structure. Nucleotide $s^{4} \mathrm{U} 8$ is the first nucleotide following the acceptor stem, and its arrangement must be tied closely to the position of the acceptor stem. Nucleotide C13 is one half of the terminal base pair of the D stem with G22, and G22 in turn is also hydrogen bonded with $\mathrm{m}^{7} \mathrm{G} 46$ to form a base triple. In addition, $\mathrm{s}^{4} \mathrm{U} 8$ is hydrogen bonded to A14, which positions it in close proximity to the C13-G21-G46 base triple. As a 
TABLE 1. Summary of experiments and calculation of apparent geometry and force constants

\begin{tabular}{lllcccc}
\hline tRNA $\left(\mathrm{kJ} \mathrm{mol}^{-1} \AA^{-2}\right)^{\mathrm{a}}$ & \multicolumn{1}{c}{ Buffer $^{\mathrm{b}}$} & $n$ & $k_{1, \text { corr }}\left(25^{\circ} \mathrm{C}\right)\left(\mathrm{sec}^{-1}\right)^{\mathrm{b}}$ & $E_{a}\left(\mathrm{~kJ} \mathrm{~mol}^{-1}\right)^{\mathrm{c}}$ & $\Delta R B D(\AA)^{\mathrm{d}}$ & $K_{r, \text { app }}$ \\
\hline tRNA $^{\mathrm{fMet}}$ & $\mathrm{HiFi}$ & 7 & $0.022 \pm 0.0007$ & $19.5 \pm 0.44$ & $0.96 \pm 0.18$ & $21 \pm 8$ \\
tRNA $^{\text {Phe }}$ & $\mathrm{HiFi}$ & 5 & $0.0036 \pm 0.0002$ & $24.8 \pm 0.71$ & $0.70 \pm 0.39$ & $50 \pm 30$ \\
tRNA $^{\text {Val }}$ & $\mathrm{HiFi}$ & 4 & $0.0077 \pm 0.0003$ & $24.6 \pm 0.56$ & $0.36 \pm 0.09$ & $190 \pm 100$ \\
& $\mathrm{~T}_{20} \mathrm{~A}_{100} \mathrm{M}_{20}$ & 4 & $0.0033 \pm 0.0001$ & $26.6 \pm 0.48$ & $0.37 \pm 0.08$ & $190 \pm 80$ \\
& $\mathrm{~T}_{20} \mathrm{~A}_{100} \mathrm{M}_{10}$ & 6 & $0.0037 \pm 0.0002$ & $25.9 \pm 0.70$ & $0.44 \pm 0.13$ & $130 \pm 80$ \\
& $\mathrm{~T}_{20} \mathrm{~A}_{100} \mathrm{M}_{7}$ & 4 & $0.0036 \pm 0.0002$ & $26.1 \pm 0.61$ & $0.43 \pm 0.12$ & $140 \pm 85$ \\
& $\mathrm{~T}_{20} \mathrm{~A}_{100} \mathrm{M}_{3}$ & 6 & $0.0038 \pm 0.0003$ & $25.8 \pm 0.62$ & $0.44 \pm 0.13$ & $130 \pm 80$ \\
& $\mathrm{~T}_{20} \mathrm{~A}_{100} \mathrm{M}_{1}$ & 5 & $0.0072 \pm 0.0003$ & $24.1 \pm 0.66$ & $0.46 \pm 0.13$ & $110 \pm 65$ \\
& $\mathrm{~T}_{20} \mathrm{~A}_{100} \mathrm{M}_{0.5}$ & 6 & $0.0055 \pm 0.0003$ & $21.9 \pm 0.65$ & $1.50 \pm 0.43$ & $9.7 \pm 6.1$ \\
& $\mathrm{~T}_{20} \mathrm{~A}_{1000} \mathrm{M}_{0}$ & 2 & $0.0062 \pm 0.0005$ & $17.7 \pm 0.63$ & $7.2 \pm 2.3$ & $0.34 \pm 0.22$ \\
& $\mathrm{~T}_{20} \mathrm{~A}_{500} \mathrm{M}_{0}$ & 3 & $0.0090 \pm 0.0004$ & $15.1 \pm 0.47$ & $14.0 \pm 3.0$ & $0.077 \pm 0.036$ \\
& $\mathrm{~T}_{20} \mathrm{~A}_{200} \mathrm{M}_{0}$ & 5 & $0.022 \pm 0.0009$ & $14.1 \pm 0.54$ & $8.6 \pm 2.0$ & $0.19 \pm 0.090$ \\
& $\mathrm{~T}_{20} \mathrm{~A}_{100} \mathrm{M}_{0}$ & 5 & $0.027 \pm 0.0010$ & $12.1 \pm 0.47$ & $15.8 \pm 3.7$ & $0.048 \pm 0.024$ \\
& $\mathrm{HiFi} \mathrm{M}$ & 3 & $0.0074 \pm 0.0003$ & $22.5 \pm 0.62$ & $0.85 \pm 0.22$ & $31 \pm 17$ \\
\hline
\end{tabular}

${ }^{\mathrm{a}}$ The force constant for the conformational movement was calculated from $E_{\mathrm{a}} /(\Delta R B D)^{2}$. The fractional uncertainty of the force constant is the sum of the fractional uncertainty of the $E_{\mathrm{a}}$ value and the $\triangle R B D$ value $(\times 2)$.

${ }^{\mathrm{b}}$ Buffers are HiFi: $50 \mathrm{mM}$ Tris $(\mathrm{pH} 7.5), 30 \mathrm{mM} \mathrm{KCl}, 70 \mathrm{mM} \mathrm{NH}{ }_{4} \mathrm{Cl}, 3.5 \mathrm{mM} \mathrm{MgCl}$, $8 \mathrm{mM}$ putrescine, $0.5 \mathrm{mM}$ spermidine; buffers abbreviated $\mathrm{T}_{x} \mathrm{~A}_{y} \mathrm{M}_{\mathrm{z}}$ : $x \mathrm{mM}$ Tris $(\mathrm{pH} 7.5), y \mathrm{mM} \mathrm{NH}{ }_{4} \mathrm{Cl}$, and $z \mathrm{mM} \mathrm{MgCl}_{2} ; \mathrm{HiFi} \mathrm{M}_{0}$ : HiFi buffer without $\mathrm{Mg}^{2+}$.

${ }^{\mathrm{c}} \mathrm{All}$ measured rate constants first were corrected for differences in the $\mathrm{T}_{1}$ excited state lifetimes. The rate constants at $25^{\circ} \mathrm{C}$ and their standard errors of estimates and the energies of activation and their uncertainties (calculated from the standard error of the slope) were determined from the regression lines of the Arrhenius plots.

${ }^{\mathrm{d}}$ The apparent $\triangle R B D$ (distance between the photoreactive bonds of $\mathrm{s}^{4} \mathrm{U} 8$ and $\mathrm{C} 13$, compared to the distance they must have for photocrosslinking) were calculated using $k_{1}$ and $E_{\mathrm{a}}$ and the proportionality constant $A$ from the expression $A^{*} e^{\left(-E_{a} / R T\right)} / k_{1}$. The constant $A$, $56 \AA \mathrm{sec}^{-1}$, was calculated as described in Materials and Methods.

consequence, changes in the orientation of the $s^{4} \mathrm{U} 8$ and C13 nucleobases will require changes in the geometry of the tRNA core.

Values of the apparent change in the internucleotide distance, $\triangle R B D$, and the activation energy $\left(E_{\mathrm{a}}\right)$ can be combined to calculate an apparent force constant for the tRNA movement. This can be done by assuming quadratic behavior for the potential energy with respect to the energy present in the structure when the $\mathrm{s}^{4} \mathrm{U} 8$ and $\mathrm{C} 13$ are in their equilibrium positions (see Materials and Methods). Rearrangement of the standard expression for the potential energy gives the force constant:

$$
K_{r, \text { app }}=E_{a} /(\Delta R B D)^{2},
$$

where $E_{\mathrm{a}}$ is the activation energy, $K_{r}$, app is the apparent force constant for a virtual bond between the centers of the photoreactive bonds, and $\triangle R B D$ is the distance displacement of the reactive bonds away from their equilibrium positions toward each other. The force constant is called apparent since it is based on the assumption that all of the geometry dependence of the rate constant is due to a distance change between the reactive bonds. The apparent force constants for tRNA ${ }^{\mathrm{fMet}}$, $\mathrm{tRNA}^{\text {Phe }}$, and tRNA ${ }^{\mathrm{Val}}$ in HiFi buffer vary from $21 \pm 8$ to $190 \pm 100 \mathrm{~kJ} \mathrm{~mol}^{-1} \AA^{-2}$ (Table 1). The large uncertainties in the force constant values come from amplification of the uncertainties in the $E_{\mathrm{a}}$ values when the exponential function of $E_{\mathrm{a}}$ is calculated.

\section{Dependence of activation energy of crosslink formation on buffer conditions}

The stability and flexibility of RNA is known to depend on the concentration of both monovalent $\left(\mathrm{K}^{+}, \mathrm{NH}_{4}{ }^{+}, \mathrm{Cl}^{-}\right)$ and divalent ions, such as magnesium and putrescine, and polyamines, such as spermidine, in solution (Herman and Westhof 1998; Misra et al. 2003; Koculi et al. 2004). Therefore alterations in the monovalent ion or $\mathrm{Mg}^{2+}$ concentrations should produce differences in the photocrosslinking rates that would reflect changes in either, or both, the flexibility and structure of the tRNA. To measure this effect, the temperature dependence experiments were repeated on tRNA ${ }^{\text {Val }}$ using buffers differing in monovalent and divalent ion concentration and identity. The first series of buffers was varied in the $\mathrm{Mg}^{2+}$ concentration $(0-20 \mathrm{mM}$ $\left.\mathrm{Mg}^{2+}\right)$ and the second series was varied in the monovalent ion concentration $\left(100-1000 \mathrm{mM} \mathrm{NH}_{4} \mathrm{Cl}\right)$. The last buffer was HiFi buffer without $\mathrm{Mg}^{2+}$ to contrast the effects of the polyamines and magnesium.

Corrections were made to the measured rate constants to account for differences in the excited state lifetimes at $25^{\circ} \mathrm{C}$ and to account for the temperature dependence of the lifetimes as described in the previous section. Plots of the rate constants versus temperature for tRNA ${ }^{\mathrm{Val}}$ irradiated in these buffers show that the rate constants increase with increasing temperature in all buffers, and Arrhenius plots are linear and show that the activation energies depend strongly on the conditions (Supplemental Material). 
Trends in the rate constants and activation energies are present in the two series of experiments that used increasing $\mathrm{NH}_{4}{ }^{+}$or increasing $\mathrm{Mg}^{2+}$ concentrations (Fig. 4). For tRNA $^{\mathrm{Val}}$ in $100 \mathrm{mM} \mathrm{NH}_{4} \mathrm{Cl}$, the activation energy is less than half its value in HiFi buffer, and the rate constant is such that the apparent distance between $s^{4} \mathrm{U} 8$ and $\mathrm{C} 13$ is $\sim 15 \AA$. As a consequence of these values, the force constant is over three orders smaller in the $100 \mathrm{mM} \mathrm{NH}_{4}^{+}$buffer compared to its value in the HiFi buffer. These parameters indicate that in the absence of $\mathrm{Mg}^{2+}$ there is a much larger flexibility in the molecule and that the structure must be significantly different than the structure in the presence of $\mathrm{Mg}^{2+}$. As the $\mathrm{NH}_{4} \mathrm{Cl}$ concentration is increased from 100 to $1000 \mathrm{mM}$, the activation energy increases by $\sim 70 \%$ to nearly $18 \mathrm{~kJ} \mathrm{~mol}^{-1}$. However, the photocrosslinking rate constant is such that the apparent $\mathrm{s}^{4} \mathrm{U} 8-\mathrm{C} 13$ distance is still $\sim 7 \AA$ in $1000 \mathrm{mM} \mathrm{NH} \mathrm{NH}_{4}$. As a consequence, the apparent force constant is only $\sim 7$ times the value it has in the $100 \mathrm{mM}$ $\mathrm{NH}_{4}{ }^{+}$buffer. This is still over 500 times less than the value in HiFi buffer or in the buffer containing $20 \mathrm{mM} \mathrm{Mg}^{2+}$.

In the buffer containing $100 \mathrm{mM} \mathrm{NH}_{4}{ }^{+}$plus $0.5 \mathrm{mM}$ $\mathrm{Mg}^{2+}$, the activation energy is nearly $22 \mathrm{~kJ} \mathrm{~mol}^{-1}$ and the rate constant is such that the apparent $\mathrm{s}^{4} \mathrm{U} 8-\mathrm{C} 13$ distance is $1.5 \AA$. These values correspond to an apparent force constant of $9.7 \mathrm{~kJ} \mathrm{~mol}^{-1} \AA^{-2}$. When the $\mathrm{Mg}^{2+}$ concentration is increased to $1 \mathrm{mM}$ there is a significant increase in activation energy that results in a significant decrease in the apparent $\mathrm{s}^{4} \mathrm{U} 8-\mathrm{C} 13$ distance and an increase in the apparent force constant. Additional increases in the $\mathrm{Mg}^{2+}$ concentration up to $20 \mathrm{mM}$ result in increases in the activation energy together with decreases in the photocrosslinking rate constants. The combination of values in the buffer containing $20 \mathrm{mM} \mathrm{Mg}^{2+}$ results in an apparent internucleotide distance that is nearly the same as it is in HiFi buffer.

tRNA $^{\mathrm{Val}}$ was also measured in a buffer containing the components of HiFi buffer but without $\mathrm{Mg}^{2+}$. Under these conditions there is a slight reduction in the rate constant and a little larger reduction in the activation energy. These values indicate a little larger distance separation between $s^{4} \mathrm{U} 8$ and $\mathrm{C} 13$ and a sixfold reduction in the apparent force constant. This result indicates that the putrescine and spermidine that are in the HiFi buffer do not replace the role of $\mathrm{Mg}^{2+}$ in the tRNA structure.

\section{DISCUSSION}

The tRNA photocrosslinking reactions show a single first order behavior indicating a single structural conformer at
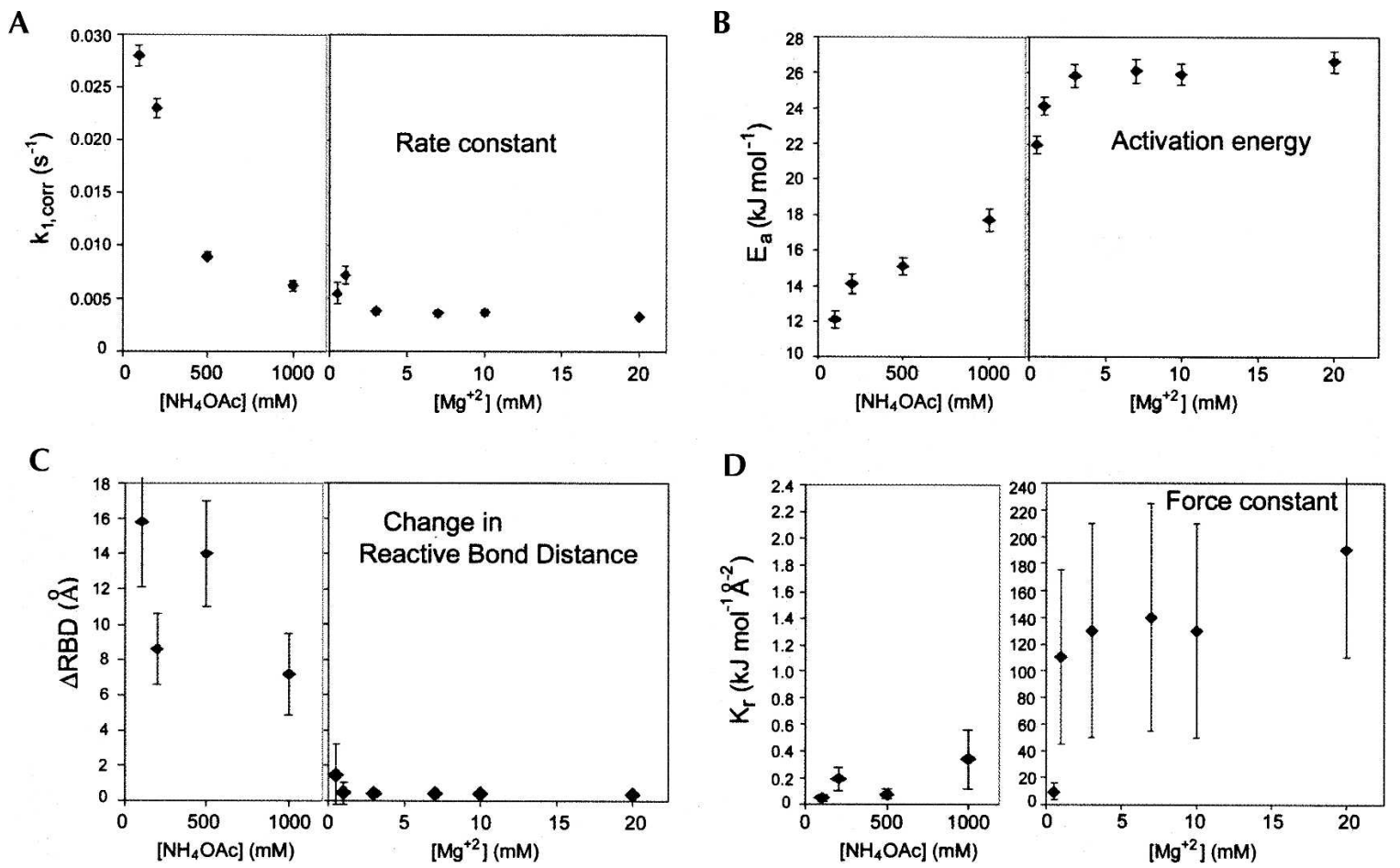

FIGURE 4. Dependence of the corrected rate constants, energies of activation, and calculated parameters on $\mathrm{NH}_{4} \mathrm{OAc}^{2}$ and $\mathrm{Mg}^{2+}$ concentrations for the tRNA ${ }^{\mathrm{Val}}{ }^{4} \mathrm{U} 8 \times \mathrm{C} 13$ crosslink. (A) Dependence of the corrected first order rate constants on $\mathrm{NH}_{4}{ }^{+}$and $\mathrm{Mg}^{2+}$ concentrations. All data in this and subsequent panels are from Table 1. (B) Dependence of activation energies on $\mathrm{NH}_{4}^{+}$and $\mathrm{Mg}^{2+}$ concentrations. $(C)$ Dependence of the $s^{4} \mathrm{U} 8-\mathrm{C} 13$ apparent distance on $\mathrm{NH}_{4}{ }^{+}$and $\mathrm{Mg}^{2+}$ concentrations. $(D)$ Dependence of force constants on $\mathrm{NH}_{4}{ }^{+}$and $\mathrm{Mg}^{2+}$ concentrations. Note that there is a 100 -fold change in scale in the left and right parts of panel $D$. For all experiments, the dependence on different $\mathrm{NH}_{4}{ }^{+}$concentrations was determined in the presence of $20 \mathrm{mM}$ Tris ( $\mathrm{pH}$ 7.5) and the dependence on different $\mathrm{Mg}^{2+}$ concentrations was determined in the presence of $20 \mathrm{mM}$ Tris (pH 7.5), $100 \mathrm{mM} \mathrm{NH}_{4} \mathrm{Cl}$. 
the $s^{4} \mathrm{U} 8-\mathrm{C} 13$ photocrosslinking site. In addition, Arrhenius behavior is seen in all of the samples with activation energies that depend on the identity of the tRNA and on the buffer conditions. These results support the model for the photocrosslinking mechanism in which the transition state for the reaction is reached during conformational excursions from an equilibrium lowest free energy structure. As a consequence the rate of reaction is determined by the conformational potential energy of the transition state rather than by the potential energy of any barrier that might occur between the lowest potential energy state and the transition state. Differences in the observed rate constants are not accounted for by the activation energies alone. From a study of the connections between internucleotide geometry and photocrosslinking frequency in ribosomal RNA, we expected that photocrosslinking rates would depend on the internucleotide distance (Huggins et al. 2005). This dependence is probably due to the fact that the excited state lifetime of the $s^{4} U$ limits the extent of the conformational excursions. The expression for the rate constant therefore contains terms for both the activation energy and the apparent displacement of the photoreaction bonds during the reaction.

The preexponential part of the equation for the rate constant could depend on the entropy change associated with reaching the transition state (Jencks 1969). In the case of the unimolecular reaction in tRNA, entropy changes could occur because of changes in the interactions with water or ions or due to changes in the conformational entropy. Since the same photochemistry occurs under all of the buffer conditions and temperatures, the reactions must go through the same transition state, so any differences in the entropy change under different conditions would have to be due to entropy differences in the equilibrium structures. The preexponential term in the equation describing the rate constant is larger by $>20$-fold for the reaction when the tRNA is in the more extended form in the absence of $\mathrm{Mg}^{2+}$ compared to the reaction when the tRNA is in the canonical form in the presence of $\mathrm{Mg}^{2+}$. If this difference were due to interactions between tRNA and water or ions, the extent of the interactions would have to be less in the extended form, which seems unlikely. On the other hand, an entropy change could be due to differences in the conformational entropy. In this case the extended tRNA form would have to possess larger conformational entropy than the canonical form and this would be consistent with a greater flexibility. However since the entropy is determined by the logarithm of the conformational space, this would require over a 20 -fold greater conformational space for the extended form compared to the canonical form. It is impossible to rule this out, but it is unlikely, since only a small fraction of the nucleotides in the tRNA seem to be involved with its conformational change (Tung et al. 1984; Nakamura and Doi 1994; Matsumoto et al. 1999). In addition, in-line probing experiments, which measure the spontaneous hydrolysis at the phosphodiester bonds and depend on the intrinsic flexibility of the nucleotide unit (Dock-Bregeon and Moras 1987; Soukup and Breaker 1999), have been done on tRNA with buffers with and without $\mathrm{Mg}^{2+}$ and show that a limited number of nucleotides have differences in reactivity, and these changes involve both increases and decreases in reactivity (data not shown). As a consequence, differences in the conformational entropy of the tRNA under different conditions could probably at best account for a small part of the variation in the preexponential term.

The corrected rate constants for photocrosslinking for tRNA $^{\text {Val }}$, tRNA ${ }^{\text {Phe }}$, and tRNA ${ }^{\mathrm{fMet}}$ in HiFi buffer are all different in spite of the fact that the activation energies are similar for tRNA ${ }^{\mathrm{Val}}$ and $\mathrm{tRNA}^{\text {Phe }}, 24.6 \mathrm{~kJ} \mathrm{~mol}^{-1}$, but are smaller for tRNA ${ }^{\mathrm{fMet}}, 19.8 \mathrm{~kJ} \mathrm{~mol}^{-1}$. The rate constant differences can be accounted for by modest differences in the $s^{4} \mathrm{U} 8-\mathrm{C} 13$ geometry in each tRNA. In addition, in $\mathrm{tRNA}^{\mathrm{Val}}$, which has been studied as a representative, the activation energies increase as the monovalent ion concentration or the $\mathrm{Mg}^{2+}$ concentration increase-the range is $12.1 \mathrm{kJmol}^{-1}$ to $26.6 \mathrm{kJmol}^{-1}$-and, under the same conditions, the values calculated for the $\mathrm{s}^{4} \mathrm{U} 8-\mathrm{C} 13$ distances decrease-the range is from $\sim 15 \AA$ to $0.36 \AA$. These changes in the properties of the tRNA under different conditions show that the rate equation links the rate constants to the conformational energy and the geometry in a self-consistent way.

The temperature dependence of the ${ }^{4} \mathrm{U}$ emission intensity at $510 \mathrm{~nm}$ provides additional evidence for flexibility changes in the tRNA. The plots of emission intensity show exponential decrease with temperature (see Supplemental Material). Emission intensity must be inversely related to the rate of the nonradiative deexcitation, which is the predominant mode for deexcitation. Arrhenius plots of the reciprocal emission intensity provide estimates of the activation energy for the deexcitation process, which are $\sim 15 \mathrm{~kJ} \mathrm{~mol}^{-1}$ in HiFi buffer and $10 \mathrm{~kJ} \mathrm{~mol}^{-1}$ in buffers without $\mathrm{Mg}^{2+}$, irrespective of the tRNA identity. The reason for the temperature dependence of the deexcitation rate is not clear, but it must come from an internal process somehow connected to the structure because the $s^{4} \mathrm{U} 8$ in the tRNA is not subject to collisional quenching or energy transfer. The activation energies for deexcitation are different than for photocrosslinking, but they are larger for tRNA in buffers with higher concentrations of $\mathrm{Mg}^{2+}$ and smaller in buffers containing only monovalent cations; this difference is consistent with the idea that the internal flexibility is changing in response to the $\mathrm{Mg}^{2+}$ content.

The photocrosslinking data indicate progressive conformational differences in the tRNA ${ }^{\mathrm{Val}}$ as the monovalent ion concentration is increased from 100 to $1000 \mathrm{mM}$ and a large change when even submillimolar $\mathrm{Mg}^{2+}$ is present. Overall the changes in the apparent distance between $s^{4} U 8$ and C13 decrease from a value of $\sim 15 \AA$ in the buffer with 
$100 \mathrm{mM} \mathrm{NH}_{4}{ }^{+}$to values of $\sim 0.4 \AA$ in HiFi buffer or in the buffer with $20 \mathrm{mM} \mathrm{Mg}^{2+}$; this last value is consistent with the structure seen in the crystal. The values of the apparent force constant for the relative movement of $s^{4} \mathrm{U} 8$ and $\mathrm{C} 13$ are $0.05 \mathrm{~kJ} \mathrm{~mol}^{-1} \AA^{-2}$ for the tRNA in $100 \mathrm{mM} \mathrm{NH}_{4} \mathrm{Cl}$ and $\sim 200 \mathrm{~kJ} \mathrm{~mol}^{-1} \AA^{-2}$ for the tRNA in the HiFi buffer or the buffer with $20 \mathrm{mM} \mathrm{Mg}^{2+}$. These values indicate an exceedingly flexible structure under the lowest ionic strength. However, even the largest of these force constants is small compared to the $\mathrm{C}-\mathrm{C}$ covalent bond stretching force constant, 1200-2000 kJ mol ${ }^{-1} \AA^{-2}$ (Weiner et al. 1986). The apparent force constants determined here are in keeping with the energy change associated with bending the tRNA in small angles.

The shape of yeast $\mathrm{tRNA}^{\text {Phe }}$ determined by transient electric birefringence in a buffer containing $15 \mathrm{mM} \mathrm{NaPO}_{4}$ ( $\mathrm{pH} 7$ ) and $0.01-10 \mu \mathrm{M} \mathrm{Mg}^{2+}$ indicated an interstem angle of $154^{\circ}$ (Friederich and Hagerman 1997). There was a large change in the tRNA behavior at $\mathrm{Mg}^{2+}$ concentrations between 10 and $200 \mu \mathrm{M}$. The terminal decay time decreased to a minimum at $200 \mu \mathrm{M} \mathrm{Mg}^{2+}$, corresponding to an interstem angle of $70^{\circ}$, and increased a little as the $\mathrm{Mg}^{2+}$ concentration was increased to $10 \mathrm{mM}$, corresponding to an angle of $80^{\circ}-90^{\circ}$. Changes in the tRNA interstem angle and flexibility were also measured by the gel electrophoretic mobility of RNA molecules with the yeast tRNA ${ }^{\text {Phe }}$ sequence (Friederich et al. 1998). Mobility differences confirmed the $\mathrm{Mg}^{2+}$ dependence of both the tRNA bend angle and the flexibility. The flexibility change could not be unambiguously calculated. However, one model predicted a 50 -fold decrease in the torsional elastic constant, a measure of the flexibility, although the values in low $\mathrm{Mg}^{2+}$ concentrations should also be affected by changes in the persistence length of the RNA (Friederich et al. 1998).

It was not possible for us to use the same ionic conditions of Friederich and Hagerman (1997) and Friederich et al. (1998) due to the instability of the tRNA at higher temperatures. However, it is likely that we are observing the same overall conformational transition in the tRNA from the extended flexible structure that it has in $0-10 \mu \mathrm{M} \mathrm{Mg}^{2+}$ to the canonical structure that it has in buffers containing at least $200 \mu \mathrm{M} \mathrm{Mg}^{2+}$. The photocrosslinking indicates an apparent distance between $\mathrm{s}^{4} \mathrm{U} 8$ and $\mathrm{C} 13$ and although this does not directly provide information about the overall extension of the tRNA structure, the changes in its value are correlated to the changes in the interstem angle determined by Friederich et al. (1998).

The fold difference in the apparent force constant calculated from photocrosslinking in buffers with high $\mathrm{Mg}^{2+}$ compared to buffers with no $\mathrm{Mg}^{2+}$ is $\sim 4000$, much larger than the fold difference estimated from the gel electrophoresis mobility measurements. This could be due to the different ionic conditions that have been used in the experiments. Alternatively, this could be due to an overestimate of the apparent $s^{4} \mathrm{U} 8-\mathrm{C} 13$ distance, especially under conditions of $0 \mathrm{mM} \mathrm{Mg}^{2+}$, which would strongly affect the calculation of the apparent force constant. The reason for a possible overestimate of the distance change is that we have used the dependence of the rate constant on internucleotide geometry as being due entirely to the distance between the photoreactive bonds. It would be reasonable that the rate constant will actually depend on a combination of changes in the distance and angle between the photoreactive bonds. Dependence on a combination of distance and angle was not used here because, in the statistical analysis of the factors for the crosslinking frequency in the rRNA, the internucleotide angle did not show a correlation to the frequency (Huggins et al. 2005).

There have been several descriptions of the flexibility of the tRNA from normal mode analysis and from a computational simulation of conformational changes. Two studies that employed normal mode analysis identified very similar lowest frequency modes that corresponded to movements of the acceptor stem and anticodon stem in the same direction and in the opposite direction of the elbow region (Nakamura and Doi 1994; Matsumoto et al. 1999). A maximum value of the bend angle due to thermal fluctuations of $\sim 5^{\circ}$ was described by Nakamura and Doi (1994), and they concluded that this bend originated from a hinge centered in the elbow region. Matsumoto et al. (1999) concluded that the movements originated at deformations around the base pair U7-A66, at the interior end of the acceptor stem, and at deformations around the base pair C28-G42 in the anticodon stem, so that the tRNA could be thought of as three blocks. The calculation of the RMS displacement values for the lowest mode and the mode frequencies are very similar in these two studies, so it is likely that there are different interpretations because of the way in which the nucleotide movements were classified.

A molecular mechanics analysis was done by Tung et al. (1984) to determine how the acceptor end-anticodon end distance could lengthen or shorten with as small as possible an energy increase. The conformational change was treated as an angular bending movement of the arms of the tRNA. A series of bending centers were identified that resulted in the low energy increases as the tRNA extended or bent acutely. For increase or decrease in the angle of bending up to $\sim 6^{\circ}$, the center of bending was located at a point halfway between the phosphates of nucleotides 8 and 49 (P8 and P49), and the energy change was $\$ 5 \mathrm{kcal}$. For additional extension up to $36^{\circ}$, the bending center was switched to the N1 atom of nucleotide 59. The total energy change for the maximum angle of bending in the core of $118^{\circ}$ was $34 \mathrm{kcal}$ $\mathrm{mol}^{-1}$. Additional extension was centered progressively around the Robertus/Klug hinge at the acceptor stem/T stem junction, at a point between P26 and P46, and then at a point between P27 and P44. The total increase in the angle was $54^{\circ}$ at an energy increase of $52 \mathrm{kcal} \mathrm{mol}^{-1}$. Since the angle in the canonical form is $82^{\circ}$, the total maximum angle between the acceptor stem and anticodon stem is $\sim 136^{\circ}$. 
The activation energy for tRNA ${ }^{\mathrm{Val}}$ in HiFi buffer associated with the $\mathrm{s}^{4} \mathrm{U} 8-\mathrm{C} 13$ movement, in which $\triangle R B D$ is equal to $0.36 \AA$, is $\sim 26 \mathrm{~kJ} \mathrm{~mol}^{-1}\left(6.2 \mathrm{kcal} \mathrm{mol}^{-1}\right)$. The bending angle associated with this distance displacement, if the bend center is at a point between P8 and P49, would be a little $<3^{\circ}$. This is in good agreement with the extent of movement under thermal energy determined by normal mode analysis (Nakamura and Doi 1994; Matsumoto et al. 1999) as well as with the energy associated with small deformations calculated by molecular mechanics (Tung et al. 1984).

Our data are also consistent with a change in the bending center as the tRNA becomes extended. As described, the $s^{4} \mathrm{U} 8-\mathrm{C} 13$ distance of $0.36 \AA$ is easy to reconcile with a bend center at P8-P49. However, for the $s^{4} \mathrm{U} 8-\mathrm{C} 13$ distance of $7 \AA$ that is measured when the tRNA is in the $\mathrm{T}_{20} \mathrm{~A}_{1000}$ buffer, the bend center must be at a location farther away from $s^{4} \mathrm{U} 8-\mathrm{C} 13$. The reason for this is that if the bend were at P8-P49, a $7 \AA s^{4} \mathrm{U} 8-\mathrm{C} 13$ distance would predict an increase in the bend angle of $42^{\circ}$, which is larger than possible for the core structure. On the other hand, if the bend center is at N1 of A59, an increase in the angle of bending would be $30 \AA$, closer to the measurements of the tRNA bend from the hydrodynamic measurements and the molecular mechanics prediction. However, for the measured $s^{4} \mathrm{U} 8-\mathrm{C} 13$ distance of $15.8 \AA$, even with the bend center at $\mathrm{N} 1$ of $\mathrm{A} 59$, an angular increase of $\sim 60^{\circ}$ is predicted that is larger than the angle calculated from the gel electrophoresis measurements or the molecular mechanics study. This suggests that part of the dependence of the photocrosslinking rate on geometry is on the angle between the bonds, which would reduce the apparent distance between $\mathrm{s}^{4} \mathrm{U} 8$ and $\mathrm{C} 13$.

Beyond small degrees of bending, there must be a significant change in the organization of the tRNA core region that involves the loss of the $\mathrm{Mg}^{2+}$ binding site. The apparent force constant for $\mathrm{s}^{4} \mathrm{U} 8-\mathrm{C} 13$ movement in HiFi buffer or in $\mathrm{T}_{20} \mathrm{~A}_{100} \mathrm{M}_{20}$ buffer is $200 \mathrm{~kJ} \mathrm{~mol}^{-1} \AA^{-2}$. If that apparent force constant described the energy when the $\mathrm{s}^{4} \mathrm{U} 8-\mathrm{C} 13$ distance increased to $15.8 \AA$, it would predict an energy increase of $\sim 47,000 \mathrm{~kJ} \mathrm{~mol}^{-1}\left(11,000 \mathrm{kcal} \mathrm{mol}^{-1}\right)$, far more than the $90 \mathrm{kcal} \mathrm{mol}^{-1}$ estimated from the molecular mechanics calculation or the $12.1 \mathrm{~kJ} \mathrm{~mol}^{-1}$ $\left(2.8 \mathrm{kcal} \mathrm{mol}^{-1}\right)$ measured in the photocrosslinking experiments when the tRNA is without $\mathrm{Mg}^{2+}$. These results point to the strong effect of $\mathrm{Mg}^{2+}$ in maintaining the structure in the tRNA core that is resistant to deformations. This is a very specific effect because there is quite a large difference in the properties of the tRNA in $\mathrm{T}_{20} \mathrm{~A}_{100} \mathrm{M}_{7}$ versus HiFi $\mathrm{M}_{0}$, which have nearly the same divalent cation concentration but have $7 \mathrm{mM} \mathrm{Mg}^{2+}$ replaced with $8 \mathrm{mM}$ putrescine and $0.5 \mathrm{mM}$ spermidine. There is a fourfold larger apparent force constant in the $\mathrm{T}_{20} \mathrm{~A}_{100} \mathrm{M}_{7}$ buffer than in the HiFi $\mathrm{M}_{0}$ buffer, so the putrescine and spermidine do not functionally replace $\mathrm{Mg}^{2+}$. The apparent force constant is much smaller when the divalent ion is replaced by even large concentrations of monovalent ions. The apparent force constant is 30 -fold larger in the $\mathrm{T}_{20} \mathrm{~A}_{100} \mathrm{M}_{0.5}$ buffer compared to the $\mathrm{T}_{20} \mathrm{~A}_{1000}$ buffer.

The experimental strategy described here provides the two measurements, $k_{1}$ and $E_{\mathrm{a}}$, to characterize the photochemical reaction. The quantitative analysis shows that the photocrosslinking rate constant can be accounted for in terms of the geometry at the photoreactive site together with the activation energy, which can be associated with the conformational energy change during the photocrosslinking reaction. These give self-consistent values for the changes in the tRNA, particularly with respect to the properties it has under conditions with different $\mathrm{Mg}^{2+}$ concentration. The experiments demonstrate a high sensitivity to the environmental conditions.

\section{MATERIALS AND METHODS}

\section{3 '-end labeling of tRNAs}

E. coli tRNA ${ }^{\mathrm{fMet}}$, $\mathrm{tRNA}^{\mathrm{Val}}$, and $\mathrm{tRNA}^{\mathrm{Phe}}$ (Sigma or Chemical Block) were 3 '-end labeled by the PPi exchange reaction using the Bacillus stearothermophilus CCA enzyme as previously described (Yue et al. 1998; Wolfson and Uhlenbeck 2002; Huggins and Wollenzien 2004). To ensure that the tRNA had fully restored ends, after incubation with $\left[\alpha-{ }^{32} \mathrm{P}\right]$ ATP under exchange conditions, ATP and CTP were added to a final concentration of $1 \mu \mathrm{M}$ and the mixture was again incubated at $55^{\circ} \mathrm{C}$ for $3 \mathrm{~min}$. The samples were then phenol and ether extracted and ethanol precipitated twice with $4 \mu \mathrm{g}$ glycogen.

\section{Irradiation procedures}

tRNAs were irradiated with light in the UVA region as described (Nanda and Wollenzien 2004). Aliquots of $3^{\prime}\left[{ }^{32} \mathrm{P}\right]$ exchangelabeled tRNA ${ }^{\text {Phe }}$, $\mathrm{tRNA}^{\mathrm{Val}}$, or tRNA ${ }^{\mathrm{fMet}}$ in microfuge tubes were submerged in a water filled sample well for irradiation with a 400 W mercury vapor lamp. The sample well was surrounded by a glass jacket containing a circulating solution of $\mathrm{Co}\left(\mathrm{NO}_{3}\right)_{2}$ to filter out wavelengths $<320 \mathrm{~nm}$ and to regulate the temperature (Isaacs et al. 1977). The light intensity in this device impinging on the microfuge tubes is $\sim 200 \mathrm{~mW} \mathrm{~cm}^{-2}$.

For time courses, $50 \mathrm{pmol}$ of either $3^{\prime}\left[{ }^{32} \mathrm{P}\right]$ end-labeled tRNA $^{\text {fMet }}$ or tRNA ${ }^{\text {Val }}$ were dissolved in $200 \mu \mathrm{L}$ HiFi buffer $(50$ $\mathrm{mM}$ Tris at $\mathrm{pH} 7.5,30 \mathrm{mM} \mathrm{KCl}, 70 \mathrm{mM} \mathrm{NH}_{4} \mathrm{Cl}, 8 \mathrm{mM}$ putrescine, $3.5 \mathrm{mM} \mathrm{MgCl}_{2}, 0.5 \mathrm{mM}$ spermidine), incubated at $10 \mathrm{~min}$ at $45^{\circ} \mathrm{C}$ followed by slow cooling, aliquoted into microfuge tubes in $100 \mu \mathrm{L}$ portions, and stored on ice until needed. The samples were preincubated at least $3 \mathrm{~min}$ at $0^{\circ} \mathrm{C}$ or $45^{\circ} \mathrm{C}$ before irradiation. Samples of $10 \mu \mathrm{L}$ were removed from each portion at $1-5,10,15$, and $20 \mathrm{~min}$. The irradiated tRNA was then precipitated with $0.5 \mathrm{M} \mathrm{NH}_{4} \mathrm{OAc}$ ( $\mathrm{pH} 5.5$ ), $4 \mu \mathrm{g}$ glycogen, and 2.5 volumes of ethanol. After precipitation, samples were separated by electrophoresis on $8 \%$ PAGE sequencing gels, with $8.3 \mathrm{M}$ urea in TBE buffer, before quantitation by ImageQuant software.

For the temperature studies, $100 \mathrm{pmol}$ of $3^{\prime}\left[{ }^{32} \mathrm{P}\right]$ end-labeled tRNA $^{\text {fMet }}$, tRNA $^{\text {Phe }}$, or tRNA ${ }^{\text {Val }}$ were dissolved in $1000 \mu \mathrm{L} \mathrm{HiFi}$ buffer and renatured for $10 \mathrm{~min}$ at $45^{\circ} \mathrm{C}$, aliquoted into $50 \mu \mathrm{L}$ 
portions, and stored on ice. The tRNAs were equilibrated at different temperatures (every $5^{\circ} \mathrm{C}$ between $0^{\circ} \mathrm{C}$ and $50^{\circ} \mathrm{C}$ ) at least $3 \mathrm{~min}$ in a separate water bath and irradiated for $1 \mathrm{~min}$ at the same temperature. After irradiation, RNA was ethanol precipitated with $4 \mu \mathrm{g}$ of glycogen as a carrier before electrophoreses.

For the experiments in the different buffers, samples were $3^{\prime}$ $\left[{ }^{32} \mathrm{P}\right]$ end-labeled and renatured in HiFi buffer as described above. The samples were then dialyzed overnight against the appropriate buffer at $4^{\circ} \mathrm{C}$, changing the buffer once. After dialysis, the samples were aliquoted, irradiated, and analyzed as described above.

\section{Calculation of the rate constant for the $s^{4} \mathrm{U} 8 \times \mathrm{C} 13$ photocrosslinking}

The amount of reaction at each time was determined by first subtracting the amount of background radioactivity present in the control (unirradiated) lane, and then dividing the amount of radioactivity in the crosslinked band by the total amount of radioactivity in the uncrosslinked and crosslinked bands RNA (Fig. 1). This number was then subtracted from the total fraction of crosslinking possible (the fractional extent of crosslinking in the samples irradiated $20 \mathrm{~min}$ at $0^{\circ} \mathrm{C}$ or $45^{\circ} \mathrm{C}$ ), and finally the difference was divided by the total fraction of crosslinking possible. This calculation yields the normalized fraction of uncrosslinked tRNA at each temperature. The natural logarithm of this value was plotted against time in the first order graphs (Fig. $2 \mathrm{C})$. The first order rate constants for the photocrosslinking reaction of $s^{4} \mathrm{U} 8 \times \mathrm{C} 13$ in both $\mathrm{tRNA}^{\mathrm{Val}}$ and $\mathrm{tRNA}^{\mathrm{fMet}}$ were calculated from the negative slope of these graphs.

\section{Calculation of first order rate constants and activation energies}

The first order rate constants for the photocrosslinking reactions at each temperature were determined from the fractional amount of crosslink product at $1 \mathrm{~min}$. The correction and normalization described above yielded a quantity that was the fraction of noncrosslinked tRNA after $1 \mathrm{~min}$ irradiation. This was converted into the rate constant by taking the natural logarithm and dividing by $60 \mathrm{sec}$.

The activation energy was then calculated by plotting the natural logarithm of the rate constants versus the inverse of temperature in degrees Kelvin as described by Equation 2. The slopes of the regression lines to those graphs are $-E_{\mathrm{a}} / R$ from which $E_{\mathrm{a}}$ values were calculated.

\section{Calculation of the preexponential $A$ factor and $\triangle R B D$}

The rate constant for photocrosslinking, $k_{1}$, and the activation energy, $E_{\mathrm{a}}$, are explicitly determined from the experiments. For reasons described in the text, the preexponential term has been separated into a term that depends on the internucleotide distance, $1 / \triangle R B D$, and a constant factor, $A$. The term $A$ was calculated using measured values for $k_{1}$ and $E_{\mathrm{a}}$ and values for $\triangle R B D$ calculated from the tRNA crystal structures. Then to calculate $A$, Equation 1 was rearranged to yield

$$
A=k_{1} \Delta R B D /\left(e^{-\left(E_{a} / R T\right)}\right) .
$$

Distances between the reactive bonds (between the midpoint of the $\mathrm{C} 4-\mathrm{O} 4$ bond of U8 and the midpoint of the C5-C6 bond) in the X-ray structures of yeast $\mathrm{tRNA}^{\text {Phe }}$ (Shi and Moore 2000), yeast tRNA ${ }^{\text {fMet }}$ (Basavappa and Sigler 1991), and yeast tRNA ${ }^{\text {Asp }}$ (Comarmond et al. 1986) were calculated and $3.4 \AA$, for the distance between aliphatic carbon atoms at van der Waals contact, was subtracted to obtain $\triangle R B D$. The calculated $\triangle R B D$ value from yeast tRNA ${ }^{\text {fMet }}$ was used with $k_{1}$ and $E_{\mathrm{a}}$ for $E$. coli tRNA $^{\mathrm{fMet}}$ to calculate $A$ and the calculated $\triangle R B D$ values from yeast $\mathrm{tRNA}^{\text {Phe }}$ and $\mathrm{tRNA}^{\text {Asp }}$ were averaged and used with $k_{1}$ and $E_{\mathrm{a}}$ values for E. coli tRNA $^{\text {Val }}$ and tRNA $^{\text {Phe }}$ to calculate $A$ values. The three $A$ values, 50.0, 98.7, and 20.0 $\AA^{-1}$ for tRNA ${ }^{\mathrm{Val}}$, $\mathrm{tRNA}^{\text {Phe }}$, and tRNA $^{\mathrm{fMet}}$, were averaged to give $56 \AA \mathrm{sec}^{-1}$, and this was used for the rest of the calculations.

\section{Calculation of the apparent force constant associated with $\mathrm{s}^{4} \mathrm{U} 8$ and $\mathrm{C} 13$ movement}

Values for $\triangle R B D$ and $E_{\mathrm{a}}$ for a tRNA under a specific condition allows calculation of an apparent force constant associated with the energy involved in the $s^{4} \mathrm{U} 8-\mathrm{C} 13$ movement. The quadratic force equation, $E=K_{r}\left(X-X_{0}\right)^{2}$, was used for the energy associated with the movement of the reactive bonds away from the separation they have in the equilibrium structure. $\triangle R B D$ has already been defined as the distance displacement between the equilibrium distance and the distance needed for photoreaction, so it is equivalent to the displacement distance in the force law. Equation 4 follows immediately.

\section{SUPPLEMENTAL DATA}

Supplemental Material can be found at http://biochem.ncsu.edu/ faculty/wollenzien/wollenzien.htm.

\section{ACKNOWLEDGMENTS}

This work was supported by funds from the College of Agriculture and Life Sciences, NC State University. Paul Agris and Keith Gagnon are thanked for help with the tRNA melting determination. Clay Clark is thanked for instructions and help with using the PTI spectrofluorimeter.

Received May 25, 2007; accepted August 8, 2007.

\section{REFERENCES}

Basavappa, R. and Sigler, P.B. 1991. The $3 \AA$ crystal structure of yeast initiator tRNA: Functional implications in initiator/elongator discrimination. EMBO J. 10: 3105-3111.

Behlen, L.S., Sampson, J.R., and Uhlenbeck, O.C. 1992. An ultraviolet light-induced crosslink in yeast tRNA ${ }^{\text {Phe }}$. Nucleic Acids Res. 20: 4055-4059. doi: 10.1093/nar/20.15.4055.

Cohn, M., Danchin, A., and Grunberg-Manago, M. 1969. Proton magnetic relaxation studies of manganous complexes of transfer RNA and related compounds. J. Mol. Biol. 39: 199-217.

Comarmond, M.B., Giege, R., Thierry, J.C., Moras, D., and Fischer, J. 1986. Three-dimensional structure of yeast tRNA-ASP. I. Structure determination. Acta Crystallogr., Sect. B 42: 272-280.

Danchin, A. and Gueron, M. 1970. Cooperative binding of manganese (II) to transfer RNA. Eur. J. Biochem. 16: 532-536.

Dock-Bregeon, A.C. and Moras, D. 1987. Conformational changes and dynamics of tRNAs: Evidence from hydrolysis patterns. Cold Spring Harb. Symp. Quant. Biol. 52: 113-121. 
Eisinger, J., Feuer, B., and Yamane, T. 1970. Luminescence and binding studies on tRNA-Phe. Proc. Natl. Acad. Sci. 65: 638-644.

Favre, A. 1990. 4-thiouridine as an intrinsic photoaffinity probe of nucleic acid structure and interactions. In Bioorganic photochemistry: Photochemistry and the nucleic acids (ed. H. Morrison), Vol. 1, pp. 379-425. Wiley, New York.

Favre, A. and Thomas, G. 1981. Transfer RNA: From photophysics to photobiology. Annu. Rev. Biophys. Bioeng. 10: 174-195.

Favre, A., Buckingham, R., and Thomas, G. 1975. tRNA tertiary structure in solution as probed by the photochemically induced 8-13 crosslink. Nucleic Acids Res. 2: 1421-1431. doi: 10.1093/nar/ 2.8.1401.

Favre, A., Ballini, J.P., and Holler, E. 1979. Phenylalanyl-tRNA synthetase induced conformational change of Escherichia coli tRNA $^{\text {Phe }}$. Biochemistry 18: 2887-2895.

Favre, A., Saintome, C., Fourrey, J.-L., Clivio, P., and Laugaa, P. 1998 Thionucleobases as intrinsic photoaffinity probes of nucleic acid structure and nucleic acid-protein interactions. J. Photochem. Photobiol. B 42: 109-124.

Friederich, M.W. and Hagerman, P.J. 1997. The angle between the anticodon and aminoacyl acceptor stems of yeast tRNA ${ }^{\text {Phe }}$ is strongly modulated by magnesium ions. Biochemistry 36: 60906099.

Friederich, M.W., Vacano, E., and Hagerman, P.J. 1998. Global flexibility of tertiary structure in RNA: Yeast RNA $^{\text {Phe }}$ as a model system. Proc. Natl. Acad. Sci. 95: 3572-3577.

Hagerman, P.J. 1997. Flexibility of RNA. Annu. Rev. Biophys. Biomol. Struct. 26: 139-156.

Herman, T. and Westhof, E. 1998. Exploration of metal ion binding sites in RNA folds by Brownian-dynamics simulations. Structure 6: 1303-1314.

Hingerty, B., Brown, R.S., and Jack, A. 1978. Further refinement of the structure of yeast tRNA ${ }^{\text {Phe }}$. J. Mol. Biol. 124: 523-534.

Holbrook, S.R., Sussman, J.L., Warrant, R.W., Church, G.M., and Kim, S.-H. 1977. RNA-ligand interactions. (I) Magnesium binding sites in yeast tRNA ${ }^{\text {Phe }}$. Nucleic Acids Res. 4: 2811-2820. doi: 10.1093/nar/4.8.2811.

Huggins, W. and Wollenzien, P. 2004. A 16 S rRNA-tRNA product containing a nucleotide phototrimer and specific for tRNA in the $\mathrm{P} / \mathrm{E}$ hybrid state in the Eschericia coli ribosome. Nucleic Acids Res. 32: 6548-6556. doi: 10.1093/nar/gkh1001.

Huggins, W., Ghosh, S.K., Nanda, K., and Wollenzien, P. 2005. Internucleotide movements during formation of $16 \mathrm{~S}$ rRNA-rRNA photocrosslinks and their connection to the $30 \mathrm{~S}$ subunit conformational dynamics. J. Mol. Biol. 354: 358-374.

Isaacs, S.T., Shen, C.-K.J., Hearst, J.E., and Rapoport, H. 1977. Synthesis and characterization of new psoralen derivatives with superior photoreactivity with DNA and RNA. Biochemistry 16: 1058-1064.

Jack, A., Ladner, J.E., Rhodes, D., Brown, R.S., and Klug, A. 1977. A crystallographic study of metal-binding to yeast phenylalanine transfer RNA. J. Mol. Biol. 111: 315-329.

Jencks, W.P. 1969. Catalysis in chemistry and enzymology. McGrawHill, New York.

Koculi, E., Lee, N.K., Thirumalai, D., and Woodson, S.A. 2004. Folding of the Tetrahymena ribozyme by polyamines: Importance of counterion valence and size. J. Mol. Biol. 341: 27-36.

Lemaigre-Debreuil, Y., Expert-Bezancon, A., and Favre, A. 1991. Conformation and structural fluctuations of a 218 nucleotides long rRNA fragment: 4-thiouridine as an intrinsic photolabeling probe. Nucleic Acids Res. 19: 3653-3660. doi: 10.1093/nar/ 19.13.3653.

Lynch, D.C. and Schimmel, P.R. 1974. Cooperative binding of magnesium to transfer ribonucleic acid studied by a fluorescent probe. Biochemistry 13: 1841-1852.

Matsumoto, A., Tomimoto, M., and Go, N. 1999. Dynamical structure of transfer RNA studied by normal mode analysis. Eur. Biophys. J. 28: 369-379.
Misra, V.K., Shiman, R., and Draper, D.E. 2003. A thermodynamic framework for the magnesium-dependent folding of RNA. Biopolymers 69: 118-136.

Nakamura, S. and Doi, J. 1994. Dynamics of transfer RNAs analyzed by normal mode calculation. Nucleic Acids Res. 22: 514-521. doi: 10.1093/nar/22.3.514

Nanda, K. and Wollenzien, P. 2004. Pattern of 4-thiouridine-induced crosslinking in $16 \mathrm{~S}$ ribosomal RNA in the Escherichia coli $30 \mathrm{~S}$ subunit. Biochemistry 43: 8923-8934.

Ogle, J.M. and Ramakrishnan, V. 2005. Structural insights into translational fidelity. Annu. Rev. Biochem. 74: 129-177.

Robison, B. and Zimmerman, T.P. 1971. A conformational study of yeast phenylalanine transfer ribonucleic acid. J. Biol. Chem. 246: 110-117.

Römer, R. and Hach, R. 1975. tRNA conformation and magnesium binding. A study of a yeast phenylalanine-specific tRNA by a fluorescent indicator and differential melting curves. Eur. J. Biochem. 55: 271-284.

Römer, R., Riesner, D., and Maass, G. 1970. Resolution of five conformational transitions in phenylalanine-specific tRNA from yeast. FEBS Lett. 10: 352-357.

Schuwirth, B.S., Borovinskaya, M.A., Hau, W.W., Zhang, W., VilaSanjurjo, A., Holton, J.M., and Cate, J.H.D. 2005. Structures of the bacterial ribosome at $3.5 \AA$ resolution. Science 310: 827-834.

Shapkina, T., Lappi, S., Franzen, S., and Wollenzien, P. 2004. Efficiency and pattern of UV pulse laser induced RNA-RNA crosslinking in the ribosome. Nucleic Acids Res. 32: 1518-1526. doi: $10.1093 /$ nar/gkh320.

Shi, H. and Moore, P.B. 2000. The crystal structure of yeast phenylalanine tRNA at $1.93 \AA$ resolution: A classic structure revisited. RNA 6: 1091-1105.

Soukup, G.A. and Breaker, R.R. 1999. Relationship between internucletide linkage geometry and the stability of RNA. RNA 5: 13081325.

Stein, A. and Crothers, D.M. 1976a. Equilibrium binding of magnesium (II) by Escherichia coli tRNAfMet. Biochemistry 15: 157-160.

Stein, A. and Crothers, D.M. 1976b. Conformational changes of transfer RNA. The role of magnesium (II). Biochemistry 15: $160-168$.

Tung, C.-H., Harvey, S.C., and McCammon, J.A. 1984. Largeamplitude bending motions in phenylalanine transfer RNA. Biopolymers 23: 2173-2193.

Turro, N.J. 1991. Modern molecular photochemistry. University Science Books, Sausalito, CA.

Weiner, S.J., Kollman, P.A., Nguyen, D.T., and Case, D.A. 1986. An all atom force field for simulations of proteins and nucleic acids. J. Comput. Chem. 7: 230-252.

Willick, G.E. and Kay, C.M. 1971. Magnesium-induced conformational change in transfer ribonucleic acid as measured by circular dichroism. Biochemistry 10: 2216-2222.

Wilms, C., Noah, J.W., Zhong, D., and Wollenzien, P. 1997. Exact determination of UV-induced crosslinks in $16 \mathrm{~S}$ ribosomal RNA in 30S ribosomal subunits. RNA 3: 602-612.

Wimberly, B.T., Brodersen, D.E., Clemons, W.M., MorganWarren, R.J., Carter, A.P., Vonrhein, C., Hartsch, T., and Ramakrishnan, V. 2000. Structure of the 30 S ribosomal subunit. Nature 407: 327-339.

Wolfson, A.D. and Uhlenbeck, O.C. 2002. Modulation of tRNA ${ }^{\mathrm{Ala}}$ identity by inorganic pyrophosphatase. Proc. Natl. Acad. Sci. 99: 5965-5970.

Yarus, M. and Smith, D. 1995. tRNA on the ribosome: A waggle theory. In tRNA: Structure, biosynthesis and function (eds. D. Soll and U. RajBhandary), pp. 443-468. American Society for Microbiology, Washington, DC.

Yarus, M., Valle, M., and Frank, J. 2003. A twisted tRNA intermediate sets the threshold for decoding. RNA 9: 384-385.

Yue, D., Weiner, A.M., and Maizels, N. 1998. The CCA-adding enzyme has a single active site. J. Biol. Chem. 273: 29693-29700. 

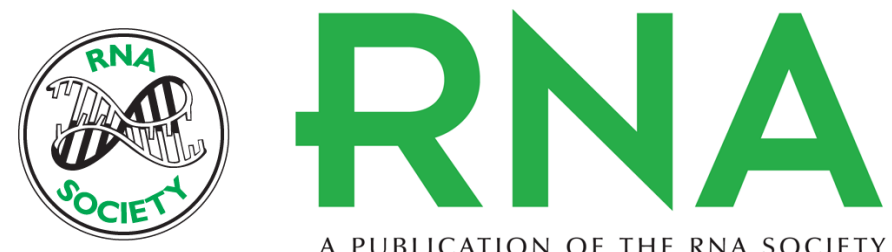

A PUBLICATION OF THE RNA SOCIETY

\section{Conformational energy and structure in canonical and noncanonical forms of tRNA determined by temperature analysis of the rate of $s{ }^{4} \mathrm{U}$ -C13 photocrosslinking}

Wayne Huggins, Tatjana Shapkina and Paul Wollenzien

RNA 2007 13: 2000-2011 originally published online September 13, 2007

Access the most recent version at doi:10.1261/rna.656907

References This article cites 47 articles, 11 of which can be accessed free at:

http://rnajournal.cshlp.org/content/13/11/2000.full.html\#ref-list-1

License

Email Alerting Receive free email alerts when new articles cite this article - sign up in the box at the Service top right corner of the article or click here. 